\title{
Augmenting conventional regional nerve block with peripheral neuromodulation using a perineural stimulating catheter
}

\author{
Vivian H. Y. Ip, MBChB, FRCA (1) - Rakesh V. Sondekoppam, MBBS, \\ MD • Ban C. H. Tsui, MD, FRCPC
}

Received: 16 October 2020/Revised: 27 December 2020/ Accepted: 28 December 2021/Published online: 22 January 2021

(C) Canadian Anesthesiologists' Society 2021

\section{To the Editor,}

Percutaneous peripheral nerve stimulation (PNS) is increasingly being used in acute pain management. ${ }^{1,2}$ With written informed consent, we report a case of using PNS via a stimulating peripheral nerve catheter and nerve stimulator to perform regional nerve blocks for the control of refractory postoperative pain.

An 80-yr-old female underwent right hip hardware removal followed by a hip arthroplasty. She had a history of fibromyalgia and chronic back pain requiring long-term hydromorphone $\left(72 \mathrm{mg} \cdot \mathrm{day}^{-1}\right.$ and gabapentin. Despite utilizing a postoperative right femoral nerve block and 132 $\mathrm{mg}$ hydromorphone on the first postoperative day (POD), she became increasingly drowsy and was immobilized because of severe pain (Figure). Inspired by previous reports showing the analgesic benefit of a short duration of PNS followed by local anesthetic injection, ${ }^{3}$ we adapted a similar approach for this case after discussion with the patient. Under ultrasound-guidance, a non-stimulating femoral nerve catheter was replaced with a stimulating catheter (StimuLong Sono Tsui, Pajunk, Germany). The catheter was sited deep to the femoral nerve with its position confirmed by hydrodissection ( $1 \mathrm{~mL}$ dextrose $5 \%)$.

\footnotetext{
V. H. Y. Ip, MBChB, FRCA ( $\varangle)$

Department of Anesthesiology and Pain Medicine, University of Alberta Hospital, Edmonton, AB, Canada

e-mail: hip@ualberta.ca
}

R. V. Sondekoppam, MBBS, MD

Department of Anesthesiology, University of Iowa, Iowa City, IA, USA

\section{B. C. H. Tsui, MD, FRCPC}

Department of Anesthesiology, Perioperative Medicine and Pain Medicine, Stanford University, Stanford, CA, USA
A nerve stimulator (Multistim SENSOR, Pajunk, Germany) was initially connected to the stimulating catheter (pulse width: $0.1 \mathrm{msec}$; frequency: $2 \mathrm{~Hz}$; current $0.3 \mathrm{~mA}$ ) with no noticeable improvement. When the current was increased to $0.5 \mathrm{~mA}$, a warm feeling was reported, and pain intensity was reduced from the hip to the knee without any motor response. Stimulation was continued for $50 \mathrm{~min}$ resulting in a reduction of the numeric pain score from 10 to 6 . Upon termination of stimulation, a loading dose of $10 \mathrm{~mL}$ mixture of $0.5 \%$ ropivacaine and $0.125 \%$ bupivacaine $(1: 1)$ was injected and followed by $0.2 \%$ ropivacaine infusion at $6 \mathrm{~mL} / \mathrm{hr}$. Ninety minutes later, the patient sat up and was satisfied with her pain control. A $30 \%$ reduction of opioid consumption was observed over the next $24 \mathrm{hr}$, which continued to decline (despite the femoral catheter being dislodged inadvertently the following day). On POD 14, the patient was discharged home on her same preoperative daily dose of $72 \mathrm{mg}$ hydromorphone.

This case illustrates the concept of utilizing a stimulating catheter designed for peripheral nerve blockade to facilitate both PNS and local anesthetic administration for analgesia purposes. While the exact mechanism and optimal neuromodulation properties (i.e., frequency, pulse width amplitude, and stimulation duration) remain uncertain, the low frequency and amplitude settings used in this case were comparable to the previously reported successful neural modulation. ${ }^{3}$ Beyond analgesic effects, similar brief neuro-stimulation has also been shown to produce a long-term benefit in enhancing sensory reinnervation. ${ }^{4}$ This case also resembles the scenario of analgesic effects from low frequency transcutaneous electrical nerve stimulation even when stimulating electrodes are applied distally and remotely from the pain-affected site. ${ }^{5}$ Hence, rather than analgesic 


\section{Hydromorphone consumption (mg)}

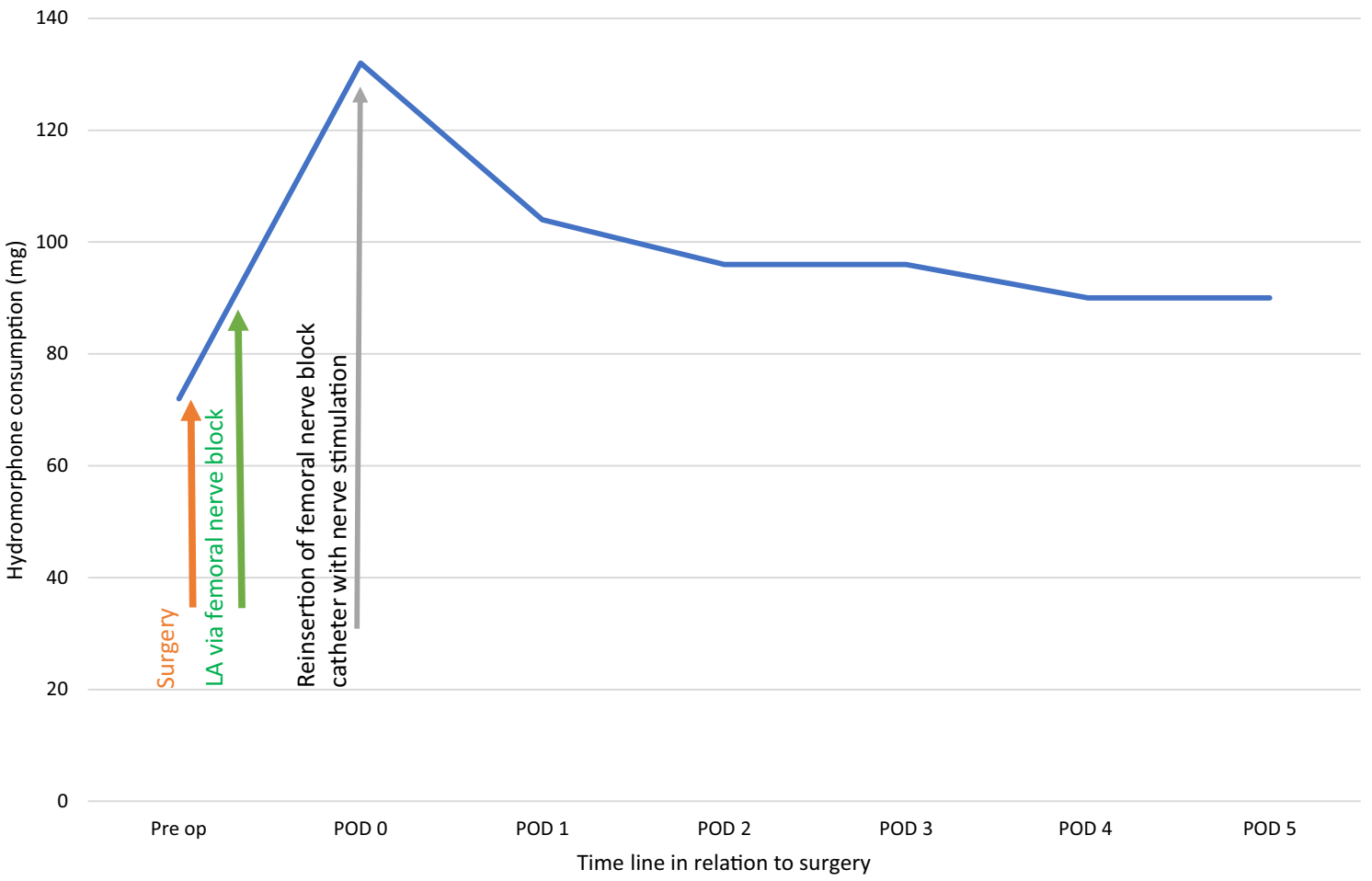

FIGURE Figure showing hydromorphone consumption on different postoperative days with the events in relation to femoral nerve block insertion and nerve stimulation. Hydromorphone consumption rapidly reduced after the activation of nerve stimulation, and continued to improve even after the cessation of nerve stimulation. Thus, the

effect following the nerve conduction principle where interruption of nerve conduction occurs, we also speculate that a possible analgesic mechanism could be due to a "gate-control theory"-related mechanism where the dorsal horns of the spinal cord serve as a gate that inhibits or facilitates transmission from the periphery to the brain. ${ }^{5}$ Pain transmission from unblocked nerves innervating the surgical site still integrate within the spinal cord; therefore, activating the gate through stimulation of unblocked nerve fibres in the femoral nerve seems a plausible mechanism. This case shows that using a readily available stimulating catheter and nerve block stimulator is a feasible way to augment pain control with neuromodulation in acute pain.

Disclosure The stimulation catheter used in this case was designed by Dr. Tsui.

Funding statement None.

Editorial responsibility This submission was handled by Dr. Hilary P. Grocott, Former Editor-in-Chief, Canadian Journal of Anesthesia. reasoning for subsequent opioid reduction remains uncertain for which might be the effect of the local anesthetic, stimulation or both. $\mathrm{POD}=$ postoperative day; Post-op $=$ postoperative $; \mathrm{LA}=$ local anesthetic.

\section{References}

1. Gabriel RA, Ilfeld BM. Percutaneous peripheral nerve stimulation and other alternatives for perineural catheters for postoperative analgesia. Best Pract Res Clin Anaesthesiol 2019; 33: 37-46.

2. Stevanato $G$, Devigili $G$, Eleopra $R$, et al. Chronic post-traumatic neuropathic pain of brachial plexus and upper limb: a new technique of peripheral nerve stimulation. Neurosurg Rev 2014; 37: 473-80.

3. Reddy CG, Flouty OE, Holland MT, Rettenmaier LA, Zanaty M, Elahi $F$. Novel technique for trialing peripheral nerve stimulation: ultrasonography-guided StimuCath trial. Neurosurgical Focus 2017; DOI:https://doi.org/10.3171/2016.12.FOCUS16475.

4. Wong JN, Olson JL, Morhart MJ, Chan KM. Electrical stimulation enhances sensory recovery: a randomized controlled trial. Ann Neurol 2015; 77: 996-1006.

5. Vance CG, Dailey DL, Rakel BA, Sluka KA. Using TENS for pain control: the state of the evidence. Pain Manag 2014; 4: 197-209.

Publisher's Note Springer Nature remains neutral with regard to jurisdictional claims in published maps and institutional affiliations. 